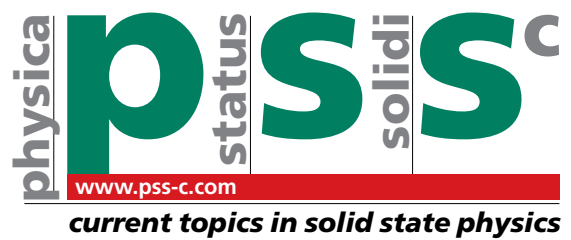

\title{
Production of nanopowders of oxides by means of fiber and pulse-periodical $\mathrm{CO}_{2}$ lasers
}

\author{
V. V. Osipov ${ }^{1}$, V. V. Platonov ${ }^{*}, 1$, V. V. Lisenkov ${ }^{1,2}$, A. V. Podkin ${ }^{1}$, and E. E. Zakharova ${ }^{1,2}$ \\ ${ }^{1}$ Institute of Electrophysics UD RAS, Amundsen st. 106, 620012 Ekaterinburg, Russia \\ ${ }^{2}$ Ural Federal University, Mira st. 19, 620002 Ekaterinburg, Russia
}

Received 30 November 2012, revised 21 February 2013, accepted 20 March 2013

Published online 29 April 2013

Keywords nanopowder, laser ablation

\begin{abstract}
* Corresponding author: e-mail platonov@iep.uran.ru
The results of investigation of $\mathrm{YSZ}, \mathrm{Nd}: \mathrm{Y}_{2} \mathrm{O}_{3}, \mathrm{Al}_{2} \mathrm{O}_{3}$ nanopowder production by laser evaporation of oxide targets in a gas current are reported in present paper. For this purpose we used the pulse-periodical $\mathrm{CO}_{2}$ laser and the continuous fiber ytterbium laser with $550 \mathrm{~W}$ and $600 \mathrm{~W}$ radiation mean power accordingly. The powders obtained by these lasers, consisted of weakly agglomerated spherical nanopartices $(\geq$ $99 \mathrm{wt} \%$ ), and $\leq 1 \mathrm{wt} \%$ of micron sized particles (drops and target fragments). Nanoparticles from various oxides produced by $\mathrm{CO}_{2}$ laser in atmospheric pressure air had close average sizes $(10 \div 16 \mathrm{~nm})$. The productivity of nanopowder synthesis by $\mathrm{CO}_{2}$ laser from YSZ $1 \% \mathrm{Nd}: \mathrm{Y}_{2} \mathrm{O}_{3}, 1 \% \mathrm{Nd}: \mathrm{Y}_{2} \mathrm{O}_{3}$,
\end{abstract}

$\mathrm{Al}_{2} \mathrm{O}_{3}$, and $\mathrm{CeGdO}$ was $23 \mathrm{~g} /$ hour, $29 \mathrm{~g} /$ hour, $24 \mathrm{~g} /$ hour and $80 \mathrm{~g}$ /hour, respectively. Unlike $\mathrm{CO}_{2}$ laser the deep melting mode is realized during evaporation of $1 \% \mathrm{Nd} \mathrm{Y}_{2} \mathrm{O}_{3}$ and $\mathrm{Al}_{2} \mathrm{O}_{3}$ targets by fiber laser. The crater depth increases up to 300 $1000 \mu \mathrm{m}$ in this mode. As a result, the target surface became very irregular and productivity of nanopowder synthesis was less, than in the case of $\mathrm{CO}_{2}$ laser. To reduce the effect of deep melting the evaporation of a target has been investigated experimentally and theoretically. As a result of our investigations we have obtained $1 \% \mathrm{Nd}: \mathrm{Y}_{2} \mathrm{O}_{3}$ nanopowder with specific surface of $70 \mathrm{~m}^{2} / \mathrm{g}$ and productivity of $23 \mathrm{~g} /$ hour at air pressure $70 \mathrm{kPa}$.

๑) 2013 WILEY-VCH Verlag GmbH \& Co. KGaA, Weinheim

1 Introduction In our days there are known many chemical and physical methods of synthesis of nanopowders. The powders synthesized by chemical methods have the low price, but usually they are strongly agglomerated. Physical methods allow receiving nanopowders with weak agglomeration. But they have law productivity and, therefore, produced nanopowder have higher price. Among them the method of laser ablation has a significant place. This technology has wide application first of all due to universality (to an opportunity to receive nanopowders of various structure) and to high quality received nanopowder.

In this paper, we have reported about the results of our researches of nanopowder production by laser ablation method.

2 Experiment The experimental setup [1] for production of nanopowder is shown in Fig. 1.

Laser radiation was focused on a target with the help of a lens, which also served as an entrance window of the chamber. As a result laser radiation heating of target surface the laser plume consisting from target material vapor appeared near the surface.

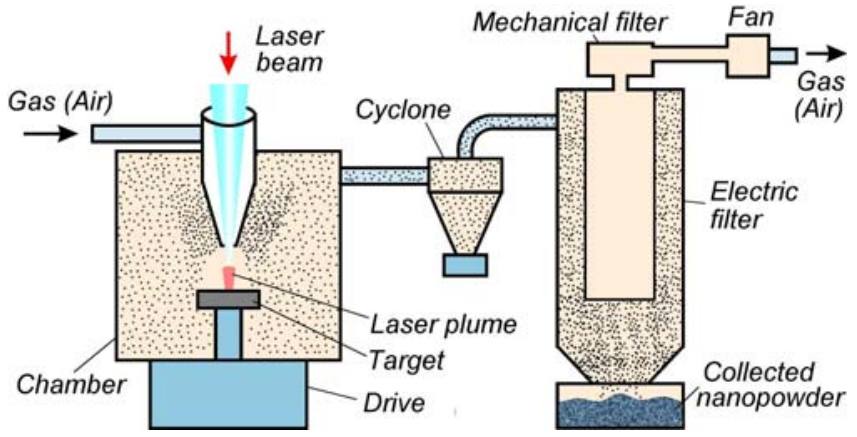

Figure 1 The experimental setup for production of nanopowder.

Laser radiation was focused on a target with the help of a lens, which also served as an entrance window of the chamber. As a result laser radiation heating of target surface the laser plume consisting from target material vapor appeared near the surface. Mixing up with air or other buffer gas the vapor was cooled. Then vapor was condensed, forming nanoparticles, which were as a suspension in the chamber. The special drive rotated a target and moved it linearly in a horizontal plane so that the laser 
beam scanned a surface of a target with constant linear speed for homogeneous treatment of surface. Here is the target before and after evaporation. The fan pumped air through the chamber and carried the nanopowder to the cyclone and further to the electric filter where the nanopowder was gathered. The afterpurification of air or gas was realized in the mechanical filter and after it came back into the chamber. Speed of a stream of gas above the target surface was approximately $15 \mathrm{~m} / \mathrm{s}$.

Table 1 Parameters of lasers.

\begin{tabular}{lcc}
\hline \multicolumn{1}{c}{ Parameter } & $\mathrm{CO}_{2}$-laser & Yb fiber laser \\
\hline Wavelength, $\mu \mathrm{m}$ & 10.6 & 1.07 \\
Peak radiation power, $\mathrm{kW}$ & $8 \div 11$ & \\
Mean radiation power, $\mathrm{W}$ & 550 & 600 \\
Pulse repetitive frequency, $\mathrm{Hz}$ & 650 & \\
Efficiency, \% & 10 & 25 \\
Power consumption, $\mathrm{kW}$ & 10 & 6.5 \\
\hline
\end{tabular}

glomerated and consisted of two fractions sharply distinguished on the sizes. The first fraction consisted of spherical nanoparticles which diameter did not exceed $40 \mathrm{~nm}$ (Fig. 2). The part of this nano-fraction was more than $99 \mathrm{wt} \%$. The part of second fraction was less then $1 \mathrm{wt} \%$. Basically, this fraction consisted of spherical particles with sizes from $1 \mu \mathrm{m}$ (or less) up to $100 \mu \mathrm{m}$ (Fig. 3). These particles are formed most probably by spraying of a liquid phase. This proposal can be validated by the fact that the chemical composition of these particles either was close to target, or had a higher concentration of component with higher boiling temperature. Nano-fraction always had deficiency of this component.

We found out interesting enough fact, that nanopowders had close size distributions under identical experimental conditions, irrespective of the target material (Fig. 4, 5). Similarity in the sizes was observed for materials with close (Nd: $\mathrm{Y}_{2} \mathrm{O}_{3}$ and $\mathrm{YSZ}$ ) and different thermo-physical properties ( $\mathrm{Nd}: \mathrm{Y}_{2} \mathrm{O}_{3}$ and $\left.\mathrm{CeGdO}\right)$.

Table 2 Received nanopowders.

\begin{tabular}{|c|c|c|c|c|c|}
\hline Target material & Nanopowder material & $\begin{array}{l}\text { Middle } \\
\text { size, } \mathrm{nm}\end{array}$ & Crystal lattice & $\begin{array}{l}\text { Productivity, } \\
\text { g/hour }\end{array}$ & $\begin{array}{l}\text { Specific en- } \\
\text { ergy consump- } \\
\text { tion, }(\mathrm{W} \times \mathrm{h}) / \mathrm{g}\end{array}$ \\
\hline \multicolumn{6}{|c|}{$\mathrm{CO}_{2}$ laser } \\
\hline $\mathrm{YSZ}\left(10.1 \% \mathrm{Y}_{2} \mathrm{O}_{3}+89.9 \% \mathrm{ZrO}_{2}\right)$ & $\mathrm{YSZ}\left(9.9 \% \mathrm{Y}_{2} \mathrm{O}_{3}+90.1 \% \mathrm{ZrO}_{2}\right)$ & 15 & Cubic & $18 \div 22$ & $20 \div 30$ \\
\hline $\begin{array}{l}\text { Mechanical mixture of } 85 \% \mathrm{Al}_{2} \mathrm{O}_{3}, \& \\
15 \% 1.65 \mathrm{YSZ}\end{array}$ & $89 \% \mathrm{Al}_{2} \mathrm{O}_{3}+11 \% 1.1 \mathrm{YSZ}$ & 17 & $\begin{array}{l}\text { Cubic \& } \\
\text { tetragonal }\end{array}$ & 20 & $20 \div 30$ \\
\hline $\mathrm{Al}_{2} \mathrm{O}_{3}$ & $\mathrm{Al}_{2} \mathrm{O}_{3}$ & $\approx 15$ & & 22 & 20 \\
\hline $\begin{array}{l}\text { Mechanical mixture of } 1 \% \mathrm{Nd}_{2} \mathrm{O}_{3} \& \\
99 \% \mathrm{Y}_{2} \mathrm{O}_{3}\end{array}$ & $1.35 \% \mathrm{Nd}_{2} \mathrm{O}_{3}+98.65 \% \mathrm{Y}_{2} \mathrm{O}_{3}$ & 22 & Monoclinic & $25 \div 28$ & $13 \div 16$ \\
\hline $\begin{array}{l}\text { Mechanical mixture of } 65.4 \% \mathrm{CeO}_{2} \& \\
34.6 \% \mathrm{Gd}_{2} \mathrm{O}_{3}\end{array}$ & $78.2 \% \mathrm{CeO}_{2}+21.8 \% \mathrm{Gd}_{2} \mathrm{O}_{3}$ & 15 & $\begin{array}{l}\text { Solution of Gd in } \\
\text { cubic } \mathrm{CeO}_{2}\end{array}$ & $60 \div 80$ & $7 \div 13$ \\
\hline $\begin{array}{l}\text { Mechanical mixture of } 47.4 \% \mathrm{Y}_{2} \mathrm{O}_{3} \& \\
52.6 \% \mathrm{Al}_{2} \mathrm{O}_{3}\end{array}$ & $37.5 \% \mathrm{Y}_{2} \mathrm{O}_{3}+62.5 \% \mathrm{Al}_{2} \mathrm{O}_{3}(\mathrm{YAG})$ & 18 & Amorphous & 24 & 20 \\
\hline $\begin{array}{l}\text { Mechanical mixture of } 0.5 \% \mathrm{Nd}_{2} \mathrm{O}_{3} \\
49.75 \% \mathrm{Lu}_{2} \mathrm{O}_{3}, 49.75 \% \mathrm{Y}_{2} \mathrm{O}_{3}\end{array}$ & $0.59 \% \mathrm{Nd}: \mathrm{Lu}_{0.93} \mathrm{Y}_{1.07} \mathrm{O}_{3}$ & 20 & Monoclinic & 25 & $20 \div 23$ \\
\hline $\mathrm{Fe}_{2} \mathrm{O}_{3}$ & $\mathrm{Fe}_{2.8} \mathrm{O}_{4}$ & 17 & Cubic & 7 & 70 \\
\hline $\mathrm{Sc}_{2} \mathrm{O}_{3}$ & $\mathrm{Sc}_{2} \mathrm{O}_{3}$ & 26 & Cubic & 19 & 26 \\
\hline \multicolumn{6}{|c|}{$\mathrm{Yb}$ fiber laser } \\
\hline $\begin{array}{l}\text { Mechanical mixture of } 0.8 \% \mathrm{Nd}_{2} \mathrm{O}_{3} \\
\& 99.2 \% \mathrm{Y}_{2} \mathrm{O}_{3}\end{array}$ & $\begin{array}{l}\delta \% \mathrm{Nd}_{2} \mathrm{O}_{3}+(100-\delta) \% \mathrm{Y}_{2} \mathrm{O}_{3}, \\
\delta=0.9 \div 2.1\end{array}$ & $16 \div 19$ & Monoclinic & $22 \div 26$ & $27 \div 32$ \\
\hline $\mathrm{Al}_{2} \mathrm{O}_{3}$ & $\mathrm{Al}_{2} \mathrm{O}_{3}$ & 20 & $(0.9 \gamma+0.1 \delta) \mathrm{Al}_{2} \mathrm{O}_{3}$ & $7 \div 8$ & $87 \div 100$ \\
\hline
\end{tabular}

For production of nanopowders we used two lasers: pulsed-periodic $\mathrm{CO}_{2}$ laser and continuous $\mathrm{Yb}$ fiber laser. Parameters of lasers are in Table 1. Parameters of received by nanopowders are shown in Table 2 . Some of these results were published in [1].

The analysis of the received powders obtained with the help of both lasers has shown that they were poorly ag- 


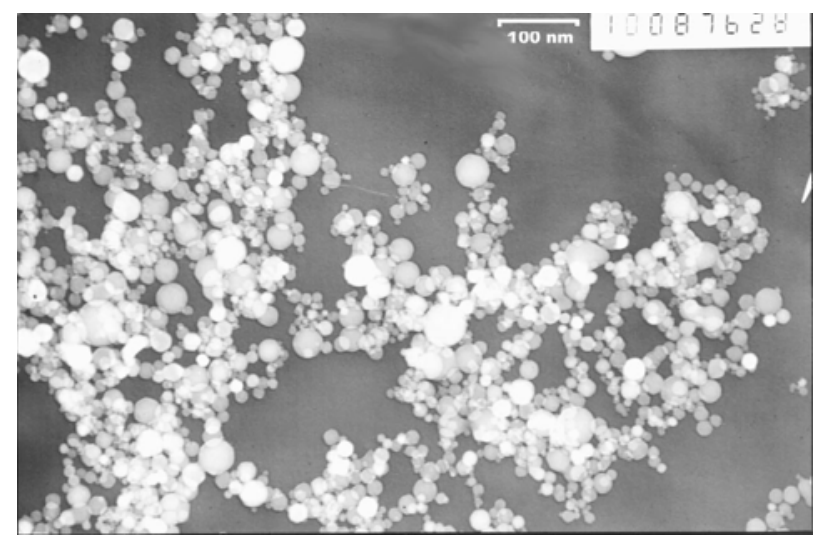

(a)

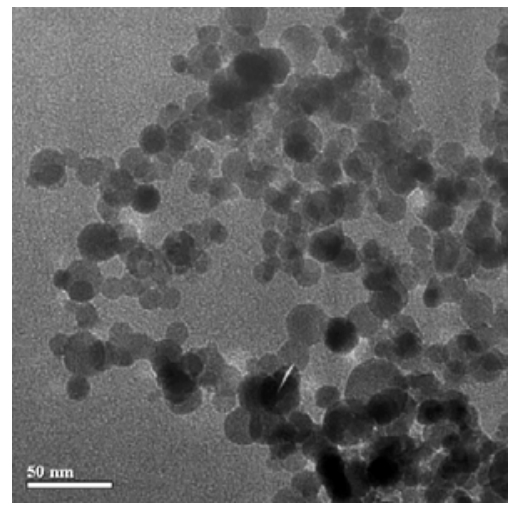

Figure 2 Photos of nanoparticles of $\mathrm{Y}_{2} \mathrm{O}_{3}$ produced by $\mathrm{CO}_{2}$ laser (a) [1] and $\mathrm{Yb}$ fiber laser (b).

In our opinion, it was caused by similar parameters of laser plumes from various targets, in particular dynamics of pressure in plumes. This similarity turns out due to a constancy of air pressure in the chamber, equal to $1 \mathrm{~atm}$. However, other variants of an explanation of this phenomenon are possible.

The size distribution of micro-drops is shown in Fig. 6. This figure will be explained below.

Another interesting experimental fact is that nanoparticles can be formed in a metastable phase, which is no typical phase at room temperature. For example the nanoparticles of yttrium oxide were obtained in monoclinic phase instead cubic phase typical for room temperature. In our opinion, the metastable phase is formed at crystallisation of nanoparticles in a laser plume, and at their further cooling there can be a phase transformation to a stable phase. For 1 mol\% $\% \mathrm{Nd}: \mathrm{Y}_{2} \mathrm{O}_{3}$ we have counted by formula (1) the characteristic transition time from a monoclinic phase to a stable cubic phase.

$$
\tau=\left(A \sqrt{T} \exp \left(-\frac{Q}{k T}\right)\right)^{-1}
$$

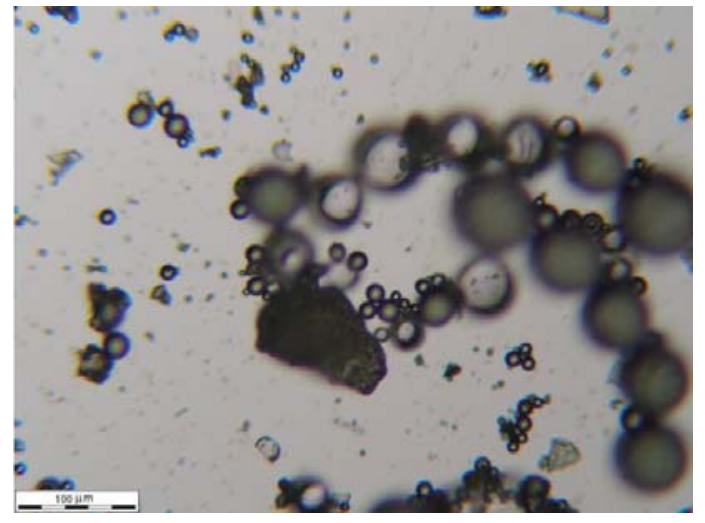

a)

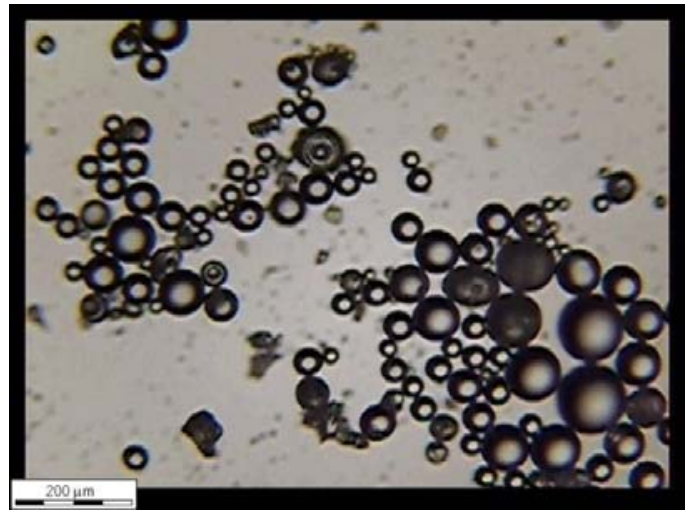

b)

Figure 3 Photos of micro drops in nanopowder produced by $\mathrm{CO}_{2}$ laser (a) and $\mathrm{Yb}$ fiber laser (b).

Values of coefficient of proportionality A and activation energies Q have been obtained from experiments on thermal annealing of the obtained powders. The dependence of characteristic transition time on temperature calculated with a help of Eq. (1) is shown in Fig. 7.

At the melting point of yttrium oxide, $2400{ }^{\circ} \mathrm{C}$ this time is minimum ( $2 \mathrm{~ms})$ and many times over exceeds a time of cooling of particles in a laser torch $(\sim 400-600 \mu \mathrm{s})$. Thus, a monoclinic phase of $1 \% \mathrm{Nd}: \mathrm{Y}_{2} \mathrm{O}_{3}$ nanoparticles "is frozen" at their fast cooling in a laser plume.

In our experiments we changed the focal distance of lens and velocity of target movement. The optimal focal distance was $40 \mathrm{~cm}$, witch provided the focal spot diameter approximately $500 \mu \mathrm{s}$.

The dependences of different physical parameters on target movement velocity are presented in Figs. 8 and 9.

In Fig. 8 there are depth of laser beam tracks on target surface for two lenses with different focus distance and specific surfaces of nanoparticles. It is well known that specific surface $(S)$ is connected with average diameter $\left(d_{B E T}\right)$ of nanoparticles by this formula:

$d_{B E T}=6 /\left(\rho\left[\mathrm{g} / \mathrm{cm}^{3}\right] \times \mathrm{S}\left[\mathrm{m}^{2} / \mathrm{g}\right]\right)[\mu \mathrm{m}]$,

where $\rho$ is the density of the material. 


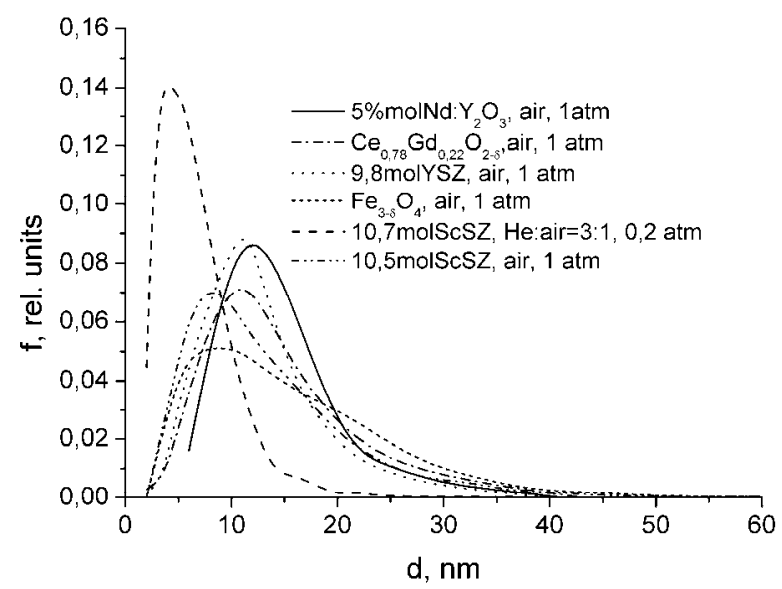

Figure 4 The grain size distribution of nanopowders produced by $\mathrm{CO}_{2}$ laser.

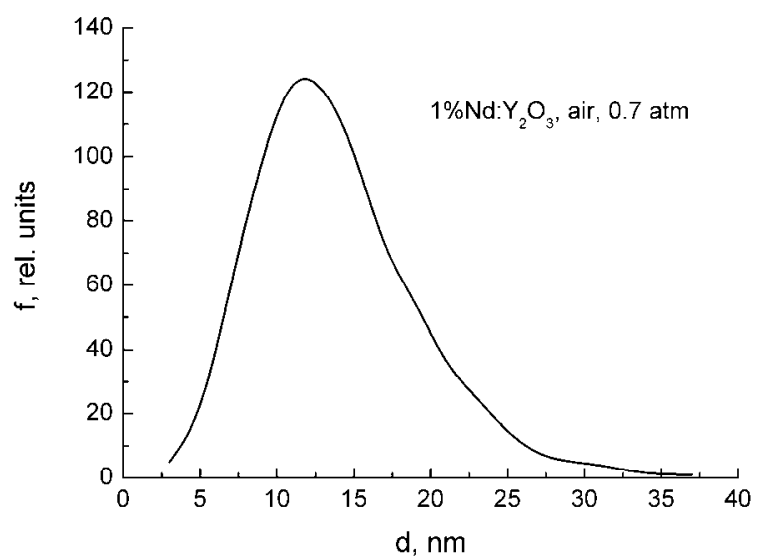

Figure 5 The grain size distribution of nanopowders produced by $\mathrm{Yb}$ fiber laser (b).

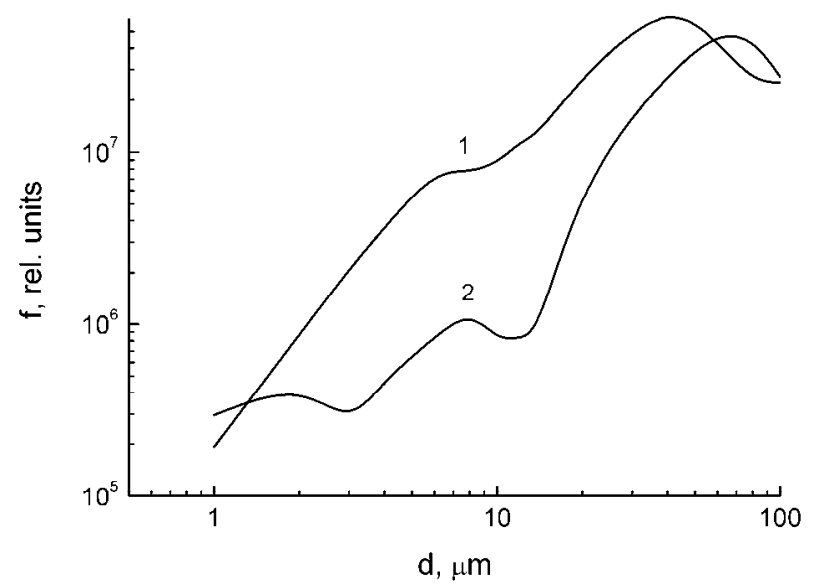

Figure 6 The size distribution of micro-drops in $1 \% \mathrm{Nd}: \mathrm{Y}_{2} \mathrm{O}_{3}$ nanopowder, (1) for $\mathrm{CO}_{2}$ laser, (2) for $\mathrm{Yb}$ fiber laser.

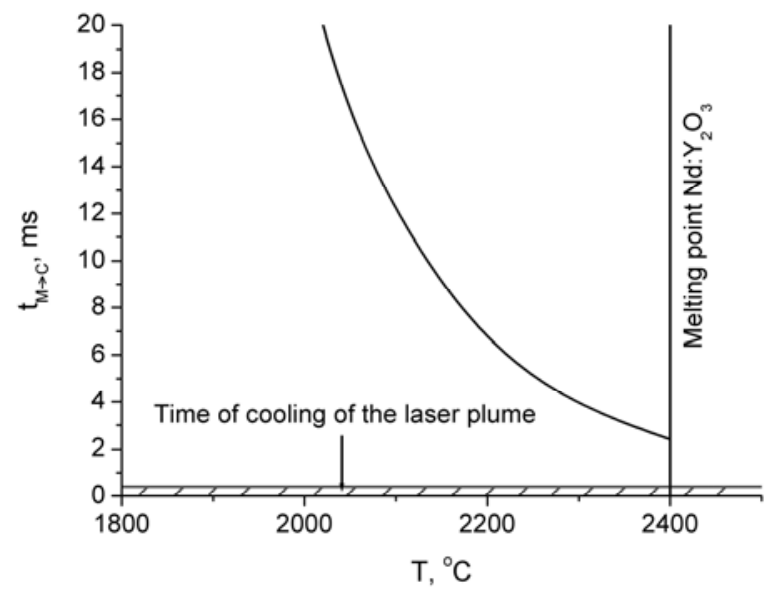

Figure 7 The dependence of characteristic time of monocliniccubic phase transition in $1 \% \mathrm{Nd}: \mathrm{Y}_{2} \mathrm{O}_{3}$ on temperature.

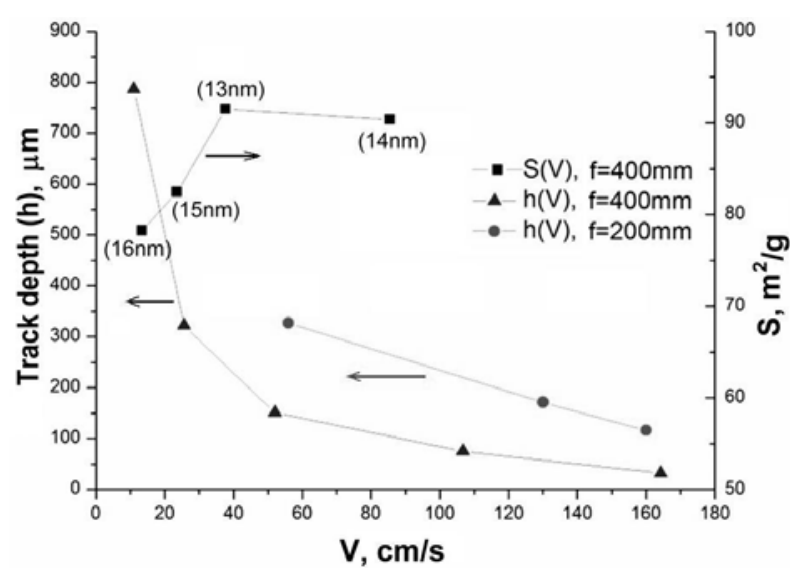

Figure 8 The depth of fiber laser beam track (h) and specific surface (S) vs. velocity of target movement.

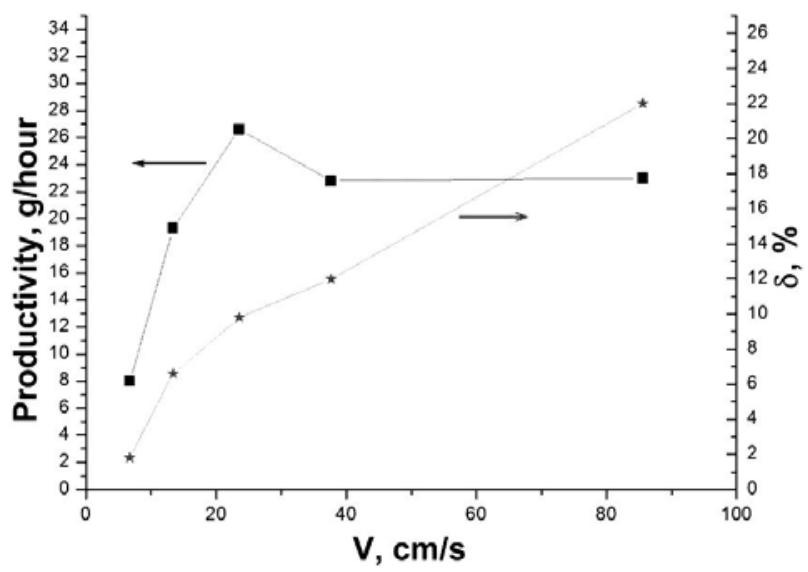

Figure 9 The productivity of nonopowder synthesis by fiber laser and the efficiency of target usage $(\delta)$ vs. velocity of target movement. 
The diameter calculated by this formula is written in brackets.

The dependences of productivity of nonopowder synthesis by fiber laser and the efficiency of target usage $(\delta)$ on velocity of target movement are shown in Fig. 9.

The curve of productivity shows that the optimum of velocity of target movement exists. In our opinion the reason of this optimum is the optimal track depth witch provides the optimal parameters of laser plume propagation and heat transition into the target.

The second curve shows the efficiency $(\delta)$ of target usage,

$$
\delta=\frac{M_{n p}}{M_{t}}
$$

where $M_{n p}$ is the mass of nanopowder received from 1 target; $\mathrm{M}_{\mathrm{t}}$ is the mass of target. This parameter increases monotoneous with increasing velocity and decreasing of track depth.

During evaporation the surface of the target has got an extremely inhomogeneous relief with holes and outgrowths looking like "forest" (Fig. 10). This is the result of instability, which is caused by the fact, that the laser radiation absorption in the hall is higher then on the outgrowth. Because of forest like relief the laser beam was not good focused on the target surface, and therefore the productivity decreased. Choosing the optimal velocity of target movement helps to reduce this instability.

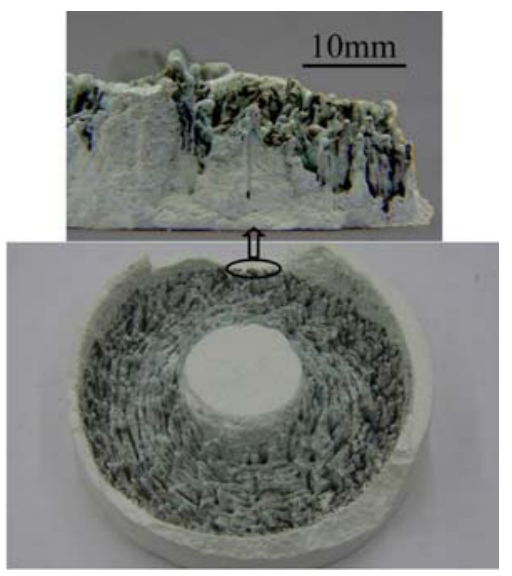

Figure 10 Photo of the target after treatment of $\mathrm{Yb}$ fiber laser.

When we used the $\mathrm{CO}_{2}$ laser for nanopowder synthesis such relief not appeared on the target surface.

In our opinion the basic distinction between two lasers consists in a ten times difference of wavelengths which cause the difference in optical constants. For example, the depth of $\mathrm{CO}_{2}$ laser radiation absorption in yttrium oxide is several microns and the depth of ytterbium laser radiation absorption in monocrystal yttrium oxide is more than $30 \mathrm{~cm}$. However the presence of macro and micro defects essentially reduces the radiation absorption depth. This sit- uation is realized in our laser targets which are a disks consisting of yttrium oxide particles sintered to each other. After several passages of laser beam along the target surface it becomes covered by crystallized with thickness of approximately $100 \mu \mathrm{m}$. This layer is more transparent for laser radiation. Thus, changing an optical transparency of surface layer of the target can cause a number of essential features of dynamics of target evaporation by fiber laser radiation

3 Calculations For the analysis of above-mentioned features we have numerically calculated the dynamics of the temperature distribution in the target. We have solved the following problem.

The laser beam passed along an axis $\mathrm{z}$ falling on surface xy of a target, consisting of two layers (Fig. 11). The external layer thickness of $0.1 \mathrm{~mm}$ was optically transparent crystallized melt, which was marked here by light grey color. Next layer was non-melted target with higher absorption index. This layer was marked by dark grey color.

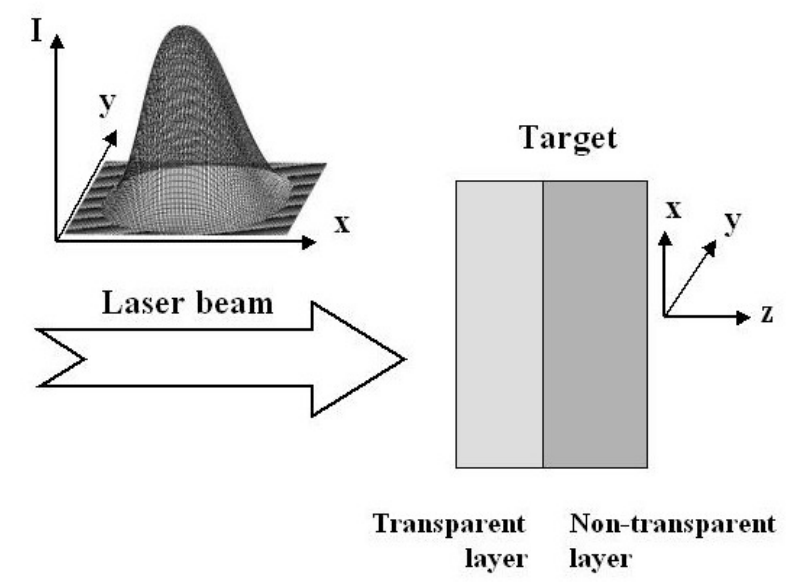

Figure 11 Geometry of the problem. The distribution of $\mathrm{Yb}$ fiber laser radiation in focal spot is in the upper left corner.

For the decision of the problem we used the threedimensional equation of heat conductivity

$$
\begin{gathered}
c(T) \frac{\partial T}{\partial t}=\nabla(\lambda(T) \nabla T)+Q \\
Q=\alpha(T) \cdot(1-R) \cdot I_{o}(x, y) \cdot \exp (-\alpha z) \cdot f(t) \\
\alpha(T)=\alpha_{0} \exp \left(\frac{T-300}{300} \xi\right)
\end{gathered}
$$

where $Q$ is the term which refer to the target heating by laser radiation, $c$ and $\lambda$ heat capacity and conductivity factors, $\rho$ density and $v$ viscosity of melt, $\alpha_{0}$ absorption index at the temperature of $300 \mathrm{~K}, R$ reflectance, $I_{0}$ focal spot intensity distribution (Fig. 11), $f(t)$ time dependent formfactor. 
The main feature of transparent dielectrics is nonlinear dependence of its absorption index on temperature (5). It nonlinearly increases with growth of temperature [2].

The results of calculations of temperature dynamics in the two-layer target for laser radiation of $700 \mathrm{~W}$ are presented in Fig. 12a.

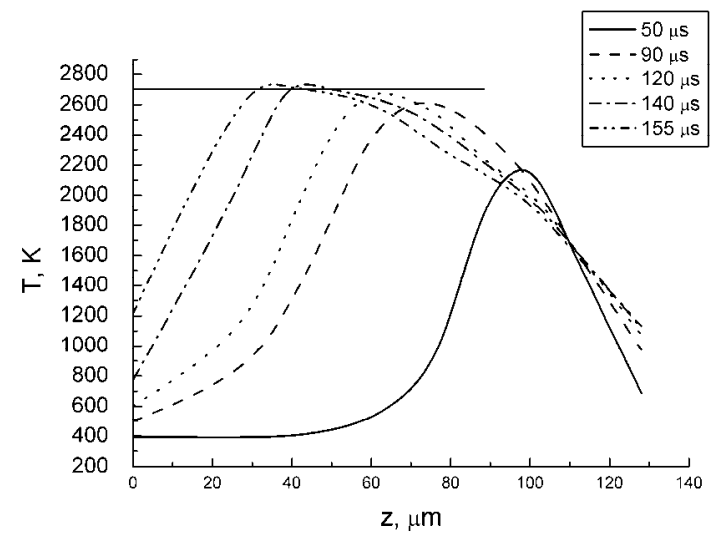

a)

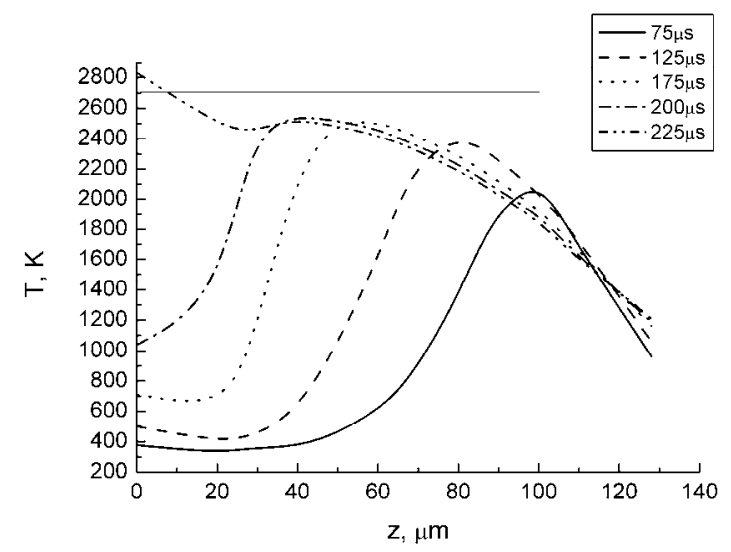

b)

Figure 12 The dynamic of temperature in two-layer target heated by fiber laser radiation of $700 \mathrm{~W}$ (a) and $500 \mathrm{~W}$ power.

Because of the big difference in absorption indexes the main heating began on layers boundary. Then, due to nonlinear dependence of absorption index on temperature the heat wave began to move to target surface. The amplitude of this wave increased and to $140 \mu \mathrm{s}$ it becomes equal to melting temperature. The melting began into the target on depth about $30 \mu \mathrm{m}$. As a result of melting the density into the target changed sharply and high mechanic pressure broke off the part of target.

At the radiation power of $500 \mathrm{~W}$ (Fig. $12 \mathrm{~b}$ ) and less the temperature maximum exceeded the melting temperature only on target surface. In this case the melting process began by the moment of time $225 \mu$ s on the surface regime of melting was realized.
Photos of craters confirming presence of two modes of melting are shown in Fig. 13.

The crater in Fig. 13a illustrates the bulk regime of melting. You can see that the crater is surrounded by broken area of visible crystal grains.

The crater in Fig. 13b illustrates the surface regime of melting. It is surrounded by a wave of crystallized melt. It is a typical situation for surface melting and evaporation.

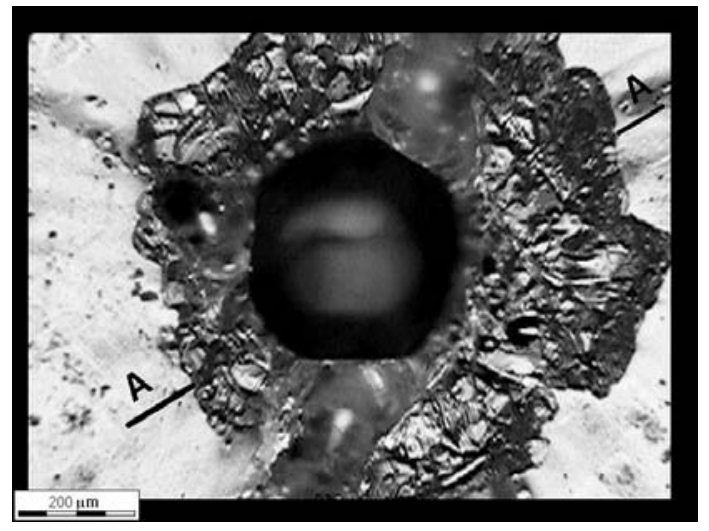

a)

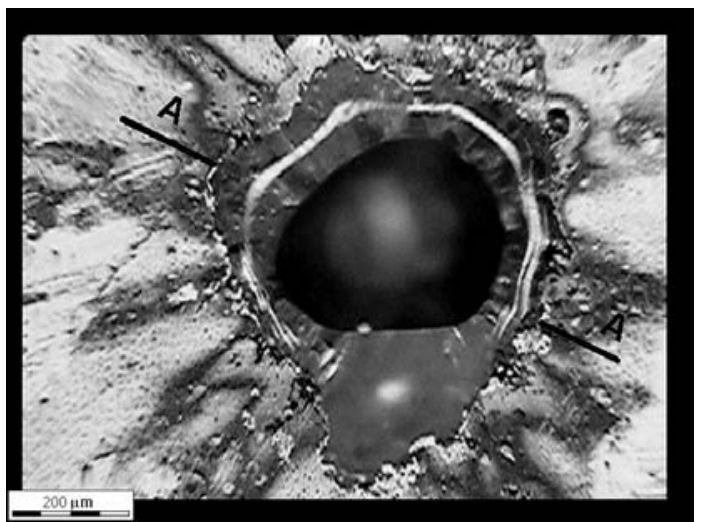

b)

Figure 13 The photos of craters made by fiber laser radiation in the target.

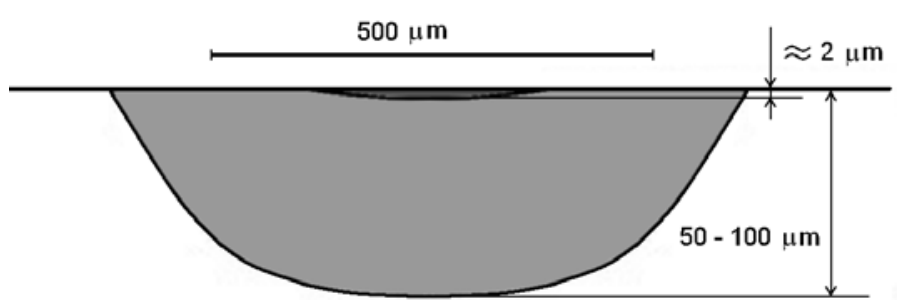

Figure 14 The melting distribution in the homogeneous target before the beginning of boiling.

With the help of our model we can to give a quality explanation of 3-mode size distribution of drops (Fig. 6). In Fig. 14 there is the melting distribution in the homoge- 
neous target directly before the beginning of boiling. It is possible to allocate two characteristic areas. The first is a melting area with characteristic depth in a range of $50-100 \mu \mathrm{m}$. It is marked by light grey color. The second is an area of a superheated liquid in metastable state. Its characteristic size is about $2 \mu \mathrm{m}$. It is marked by dark grey color. In this area the nuclei of a steam phase are formed. In such steam nuclei the pressure is high enough to pull the drop from melt surface. Such mechanism of evaporation is known and named as phase explosion. The size of such drops should be about $1 \mu \mathrm{m}$, comparable with depth of metastable area. It corresponds to the first maximum of distribution function. Larger drops are formed as a result of melting inside a target with the subsequent breaking of a solid target part. This event causes a spraying of melt. Results of our calculations show, that the characteristic size of the liquid phase formed inside the target is approximately $7-10 \mu \mathrm{m}$, which corresponds to the second maximum. The largest drops are formed due to an exit of heated air in a porous part of the target outside through the melt which size is $50-100 \mu \mathrm{m}$, which approximately corresponds to the third maximum of distribution function $80 \mu \mathrm{m}$.

\section{Conclusion}

1. The developed technology allows receiving nonagglomerated nanopowders with narrow size distribution, both from simple substances, and different mixes.
2. The nanoparticles size distributions are sufficiently close irrespective of target material at the same parameters of laser pulse and other equal conditions.

3 . The distribution of droplets by their size in case of the fiber laser has 3 maxima at 2, 8 , and $80 \mu \mathrm{m}$; this is caused by the different physical reasons.

4. In $\mathrm{Nd}: \mathrm{Y}_{2} \mathrm{O}_{3}$ targets with non-uniform transparency the movement of a thermal wave to the target surface under the influence of the fiber laser was found out. It is shown that at average power of laser radiation of $700 \mathrm{~W}$ and the power density of $5.6 \times 10^{5} \mathrm{~W} / \mathrm{cm}^{2}$ and duration more than $150 \mu \mathrm{s}$ the temperature in the maximum of thermal wave can exceed the fusion temperature of the target. It leads to sharply increasing of pressure in the area of melting and to a split of a part of the target

Acknowledgements The work was supported by Presidium of UD RAS and RFBR grant No. 11-08-00005-a.

\section{References}

[1] V. V. Osipov, Yu. A. Kotov et al., Laser Physics 16, 116 (2006).

[2] Yu. K. Danileiko, A. A. Manenkov, A. M. Prokhorov et al., Soviet Phys. JETP 36, 541 (1973) 